\title{
Yield and Fruit Size Comparisons in the First Six Crops of 16 Mango Varieties'
}

\author{
W. Pennock, A. Torres-Sepulveda, J. López-Garcia, I. Reyes-Soto, S. \\ Valle-Lamboy, A. Cedeño-Maldonado, and G. Jackson ${ }^{2}$
}

\section{INTRODUCTION}

Mangos constitute one of the crops which can be grown profitably in Puerto Rico. Mattern, Pennock and Valle ${ }^{3}$ have shown that excellent prices, ranging from $35 \&$ to $65 \&$ per pound, can be obtained throughout the mango season in the New York wholesale market where a large volume of trade in mangos can be accomodated without unduly depressing prices. A substantial market also exists in local supermarkets with reasonably high prices for high quality mangos as shown by Mattern and Pennock.4 Clean, anthracnose-free fruit can be produced on the south coast of Puerto Rico with little or no spraying. In competitive areas, such as the state of Florida, spraying is required as frequently as 20 times per year.

Little or no information is available, however, with respect to the production and fruit size of high quality varieties of mangos grown under conditions of the south coast of Puerto Rico of the kinds that command good prices on the New York market. The present paper is intended to furnish such information. A mango varietal comparison experiment was set out in August 1960 on the Fortuna Agricultural Experiment Substation farm near Juana Diaz, P.R. for the purpose of determining which of the included varieties are best suited for commercial mango production in Puerto Rico.

The productive capacity of these varieties is, of course, the primary concern of this experiment. Other commercially desirable attributes, however, such as large fruit size and consistency of bearing, also were investigated. Considerable data in parameters reflecting tree size and rate of growth was annotated because both characteristics are interrelated closely with the productive capacity of a variety. These tree measurements are being subjected to continued study. The matter of tree size and rate

1 Manuscript submitted to Editorial Board February 4, 1972.

2 Horticulturist, Associate Horticulturist and Administrator, Fortuna Substation, Assistant Agronomist, Research Assistant, Assistant Agronomist, Assistant Horticulturist and Associate Horticulturist, respectively, Agricultural Experiment Station, Mayagüez Campus, University of Puerto Rico, Río Piedras, P.R.

${ }_{8}$ Mattern, F., Pennock, W. and Valle-Lamboy, S., Supplying the New York Market with Puerto Rico Quajity Mangos, J. Agr. Univ. P.R. 56(1): 1-10, Jan. 1972.

1 Mattern, F. and Pennock, W., The Potential Market for Improved Varieties of Mangos in Puerto Rican Supermarkets, J. Agr. Univ. P.R. 55(2): 153-60, Apr. 1971. 
of growth cannot be altogether ignored; therefore, in addition to yield comparisons on a single tree basis, per acre yields also have been included wherein spacing was adjusted according to the tree-crown diameters.

\section{eXPerimental PROCEDURe}

Sixteen varieties were included in the experiment, which encompassed eight replications, each of which included four trees. There were, therefore, 32 trees of each variety, making a total of 512 trees planted at 30 feet by 30 feet spacing. The planting was set as a partially balanced incompleteblock design. The varieties were grafted on rootstocks of the variety Colombo Kidney, which is polyembryonic and usually produces seedlings which are true to type. The soil is primarily San Anton silty loam, shallow phase $^{5}$ butsome areas merge into Aguilita stony clay, shallow phase ${ }^{6}$ underlain by limestone. In consequence, some of the trees were affected adversely reducing their size, lowering yields, and in several instances resulting in death. Tree size measurements were taken on a repetitive basis and yields were recordered tree by tree thus permitting alternative methods of analysis.

Crown diameters were measured to the nearest centimeter. The procedure consisted of taking four measurements with a tape extended horizontally from the center of the tree trunk to the furthermost radial distance reached by the branch tips in each of the four cardinal directions. A vertical ruler with a spirit level was used to prolong downward the line of the branch tip periphery. The four measurements were then added, divided by 2 to obtain mean diameter and the result converted to the nearest tenth of a foot.

\section{EXPERIMENTAL RESULTS}

Table 1 shows the mean annual and total production per tree for each variety for the first six commercial crops of the experiment. The mean

s The San Anton series are soils of the dry, well drained river flood plains. The silty loam has a friable brown granular silt loam surface and has fairly high organic matter content. The typical soil is one of the best in Puerto Rico for the production of sugarcane but the shallow phase is underlain by gravel at a depth of less than 30 inches, greatly reducing yields which are more or less directly proportional to the depth of the gravel.

${ }^{6}$ Aguilita clay is one of the extensive soils derived from soft limestone in the arid and semiarid southwestern part of the island. In an average location this soil has a friable mellow granular calcareous dark grayish-brown clay surface soil 6 inches deep which gradually changes to a friable mellow granular light-gray clay loam or clay subsoil about 8 inches thick. This layer rests on gray medium soft porous limestone. In drier areas the surface soil is shallower, contains less organic matter and is lighter in color. The stony clay, shallow phase, is not only more shallow than the typical soil but also more stony. 
production per tree per year for all varieties taken together is also shown. As may be seen, the yearly means for each variety increased markedly but irregularly with increased age of the trees. Some varieties, including Kent and Haden, varied quite markedly whereas others such as Irwin and Lippens increased more regularly.

In figure 1 , the yearly means for all varieties together, as well as those of Kent and Irwin separately, are plotted against elapsed time. As may

TABLE 1.-Mean production per tree in the first six crops of 16 mango varielies planted for comparison ${ }^{1}$

\begin{tabular}{|c|c|c|c|c|c|c|c|}
\hline \multirow{2}{*}{ Variety } & \multicolumn{6}{|c|}{ Mean production per tree per year (pounds) } & \multirow{2}{*}{ Total } \\
\hline & 1965 & 1966 & 1967 & 1968 & 1969 & 1970 & \\
\hline Earlygold & 12.97 & 20.00 & 74.71 & 42.64 & 104.15 & 145.76 & 400.23 \\
\hline Edward & 4.81 & 21.30 & 43.01 & 33.38 & 66.86 & 75.49 & 244.85 \\
\hline Eldon & 32.85 & 8.12 & 96.28 & 156.20 & 27.78 & 239.98 & 561.21 \\
\hline Haden & 31.30 & 3.55 & 58.43 & 92.96 & 23.60 & 191.64 & 401.48 \\
\hline Irwin & 28.80 & 28.48 & 103.94 & 93.09 & 117.87 & 174.64 & 546.82 \\
\hline Jacquelin & 4.43 & 9.12 & 36.59 & 32.40 & 79.44 & 120.22 & 282.20 \\
\hline Keitt & 20.20 & 4.01 & 86.73 & 104.56 & 32.09 & 225.73 & 473.32 \\
\hline Kent & 48.16 & 1.10 & 61.74 & 127.62 & 18.17 & 237.00 & 493.79 \\
\hline Lippens & 27.51 & 28.04 & 59.89 & 117.35 & 122.61 & 184.10 & 539.50 \\
\hline Palmer & 15.89 & 0.33 & 50.77 & 101.03 & 45.03 & 201.43 & 414.48 \\
\hline Parvin & 12.09 & 6.24 & 81.63 & 86.96 & 64.17 & 201.43 & 452.52 \\
\hline Pillsbury & 22.01 & 16.44 & 64.96 & 83.62 & 79.94 & 54.87 & 321.84 \\
\hline Ruby & 14.40 & 16.51 & 90.23 & 89.29 & 196.36 & 193.34 & 600.13 \\
\hline Santaella & 10.80 & 7.91 & 63.89 & 102.73 & 40.98 & 144.91 & 371.22 \\
\hline Sensation & 33.78 & 7.69 & 117.72 & 126.62 & 86.64 & 266.86 & 639.31 \\
\hline Zill & 10.69 & 23.68 & 95.45 & 70.41 & 74.14 & 130.29 & 404.66 \\
\hline Total & 330.69 & 202.52 & $1,185.97$ & $1,460.86$ & $1,179.83$ & $2,787.69$ & $7,147.56$ \\
\hline Mean & 20.67 & 12.66 & 74.12 & 91.30 & 73.74 & 174.23 & 446.72 \\
\hline
\end{tabular}

1 Trees set out March-August 1960.

be observed, the annual production of Kent was subject to violent ups and downs whereas that of Irwin was more regular, giving a jagged yet fairly well-defined $J$-shaped curve, indicative of some accelerated increase in yield with increased age of trees. The means for all varieties gave an intermediate pattern, somewhat more jagged than that of Irwin, but still suggestive of a $\mathrm{J}$-shaped curve.

As a preliminary step, the mean yields of all varieties were subjected to regression analysis on age of tree. The best fitting straight line conformed to the following formula:

$$
Y=-133.02+27.66 X,
$$




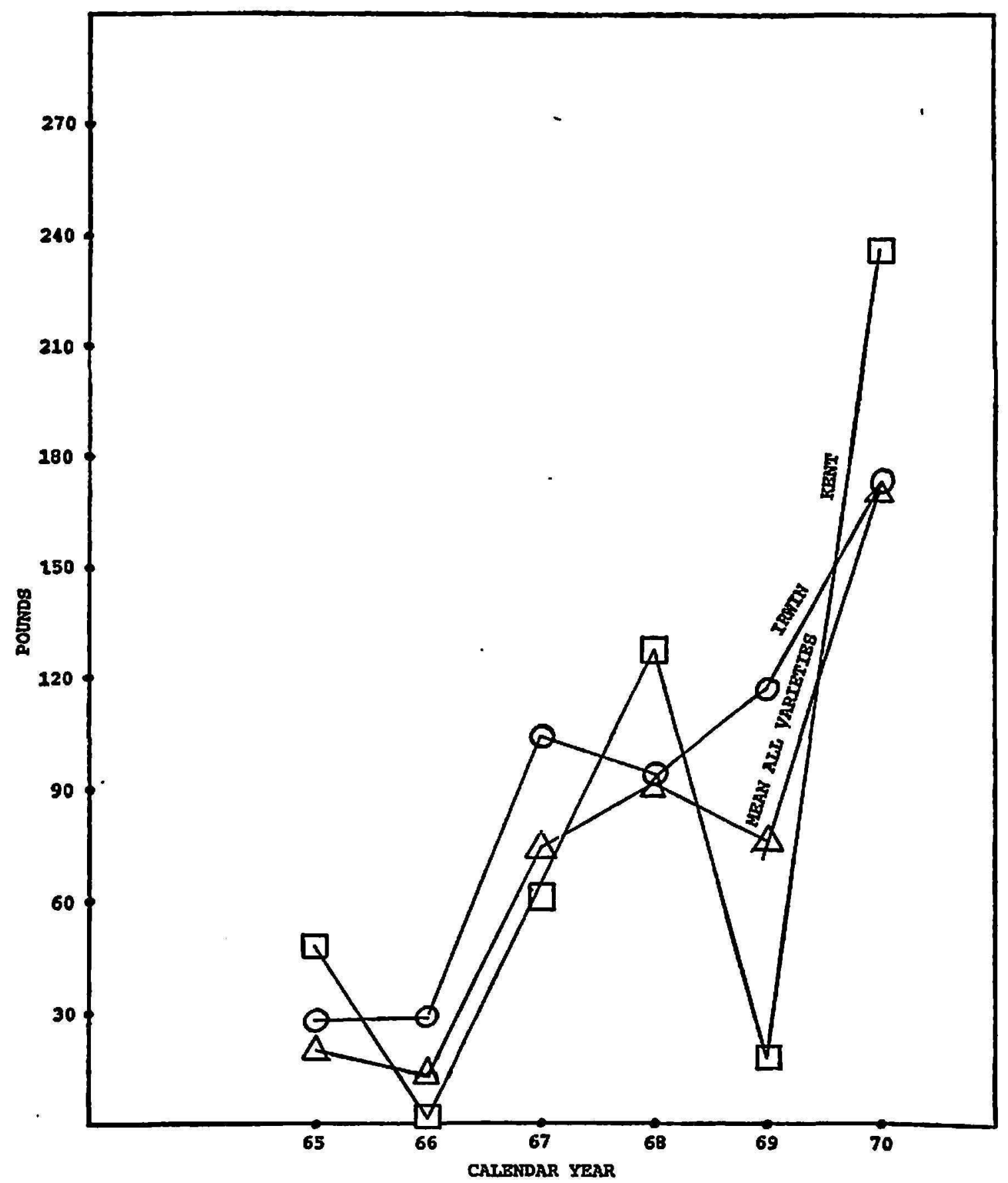

Fia. 1.-The pattern of successive yearly crops for Kent and Irwin, separately; and for the mean of all varieties taken together.

where $Y$, the dependent variable, is the mean annual yield in pounds of fruit per tree, and $X$ is the age of the tree in years. Thus the best estimate of the assumed constant annual increase in yield is 27.66 pounds of fruit per tree.

The best fitting parabola with its origin on the $Y$-axis, representing the regression on the square of the age of the tree conformed to the following 
formula:

$$
Y=-35.80+1.86 X^{2}
$$

where again $Y$ is the yield per tree and $X$ is the age of the tree.

A best fitting parabola representing the influence of the age of the tree on its yield, conformed to the following formula:

$$
Y=82.61-32.98 X+4.04 X^{2},
$$

where again $Y$ is the yield and $X$ is the age of the tree.

The coefficients of determination amounted to 0.7900 for the straight line; 0.8155 for Equation 2, and 0.8260 for Equation 3. In other words, Equation 2 fitted the data slightly better than the straight line and Equation 3 fitted it slightly better than Equation 2 but the difference in goodness of fit is very small. However, the $F$ values amounted to 15.05 for the straight line; 17.68 for Equation 2 and only 7.12 for Equation 3. The first two were significant at the 5-percent level, the latter not significant. This is simply a consequence of the low number of observations involved, which provide a total of only 5 degrees of freedom. The simple regression of the straight line and Equation 2 used only 1 degree allowing 4 for error whereas Equation 3 used 2 degrees allowing only 3 for error. It thus is quite probable when data for 1 or 2 additional years becomes available, an equation of the last type will attain significance.

Figure 2 is a graphic representation showing the mean yields per tree per year for the first six crops, as well as the linear and the two parabolic regressions of yields on age of tree. As may be observed, the pertinent segments of all three configurations fit the yield data acceptably. Annual yields on the basis of previous experience, if recorded over a long period, are expected to conform with a sigmoidal curve. They are expected to start slowly at first, then increase more rapidly for a period, and drop off later as the trees become crowded. In the present case with the data available, a straight line is equally satisfactory to explain the yield increase as the two curves which were tried. The data gathered show that mangos in general, when planted in similar locations in the south coast of Puerto Rico, can be expected to bear their first commercial crop in about 5 years from setting out. On the average this first crop would be expected to amount to about 5 pounds of fruit per tree, increasing by about 28 pounds of fruit per year per tree during the succeeding five crops. On a per acre basis at 25 feet by 25 feet spacing this would amount to 350 pounds on the fifth year with a yearly increase of 1,960 pounds. On this basis, the sixth crop would amount to about 5 tons per acre and the total for all six crops to 151/2 tons. 


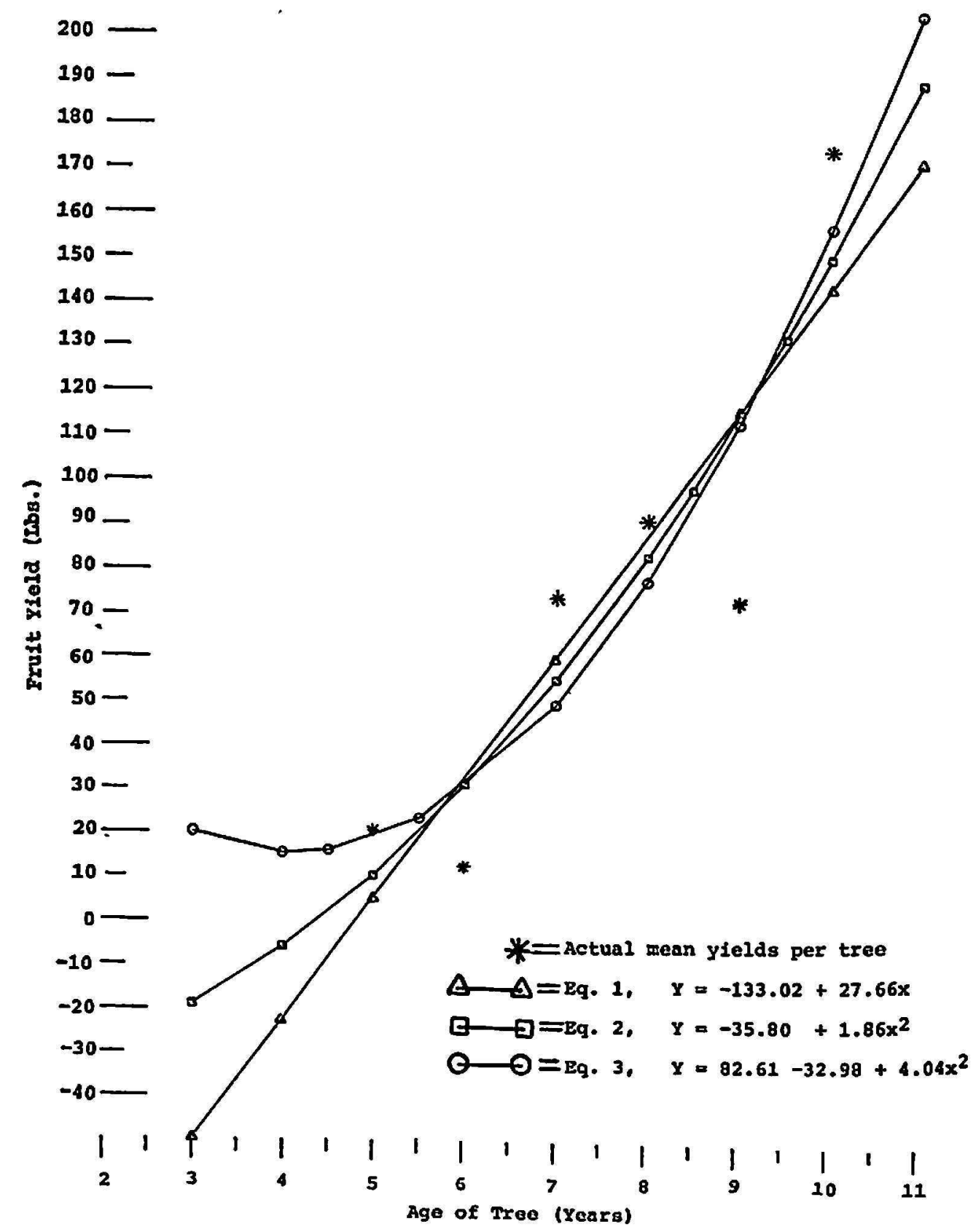

Frg. 2.-The mean annual yields per tree for all mango varieties in each of the first six crops after planting as well as three graphic representations of regression of yields on age of tree.

The degree of alternate bearing, which is characteristic of a mango variety, is a matter of considerable commercial importance. We have therefore endeavored to rate the performance of the different varieties with regard to this undesirable trait. For this purpose we have used the difference in yields from 1 year to the next expressed as percentage of the mean yield for the 2 years being compared. This serves as an index of variation from 1 year to the next. Various such indices for several successive years can then be used to calculate a mean index. This can be done for 
each tree separately, followed by calculating varietal mean indices from them or they may be calculated directly from the varietal mean yields for succeeding years. We have used both these methods. In addition, it was learned that when the individual trees were used, and the indices were subjected to an analysis of variance using the partially balanced block design, both varieties and blocks gave a highly significant $F$ value. The indices therefore were adjusted to eliminate the effect of blocks. Table 2 shows the three sets of indices obtained. Column $A$ in this table consists

TABLE 2.-Varietal indices of inconsistency in bearing and percent of total variation retained by the index derived from the means

\begin{tabular}{lcccc}
\hline Variety & $\begin{array}{c}\text { based on original } \\
\text { tree yields }\end{array}$ & $\begin{array}{c}\text { Based on adjusted } \\
\text { tree yields }\end{array}$ & $\begin{array}{c}\text { b- } \\
\text { bean on } \\
\text { meen yelds }\end{array}$ & $\begin{array}{c}\text { D- } \\
\text { C } \div \text { A }\end{array}$ \\
\hline Kent & Index & Index & Index & Percent \\
Eldon & 169 & 167 & 154 & 91 \\
Palmer & 147 & 139 & 138 & 93 \\
Haden & 173 & 170 & 131 & 75 \\
Keitt & 156 & 157 & 131 & 83 \\
Sensation & 152 & 160 & 118 & 77 \\
Santaella & 118 & 124 & 89 & 75 \\
Parvin & 139 & 148 & 80 & 57 \\
Earlygold & 132 & 130 & 75 & 56 \\
Jacquelin & 124 & 117 & 65 & 52 \\
Edward & 112 & 106 & 65 & 58 \\
Zill & 110 & 109 & 59 & 53 \\
Pillsbury & 109 & 104 & 57 & 52 \\
Ruby & 124 & 127 & 51 & 41 \\
Lippens & 115 & 111 & 45 & 39 \\
Irwin & 119 & 117 & 40 & 33 \\
\hline
\end{tabular}

of the initial varietal indices obtained from individual tree performance; column $B$ consists of these same indices after adjustment to remove the effect of blocks; and column $\mathrm{C}$ consists of the indices obtained from the varietal means. The varieties have been placed in descending order in accordance with the data in column C. Column D consists of the indices in column $\mathrm{C}$ expressed as percentages of those in column $\mathrm{A}$. The net varietal index derived from the mean appears to be the result of two different tendencies which could be separate varietal attributes. The first tendency consists of the extent of total variation in the individual tree yields in successive years, the second tendency is for different trees of the same variety to respond alike on any specific year, giving high or low yields in concert. Column D permits a better appreciation of this matter in that it shows 
what percentage of the total variation from the individual trees is included in the net variation index which was derived from the varietal mean yields. As may be appreciated, these range from slightly above 90 percent for the varieties Kent and Eldon, to slightly above and below 40 percent for the varieties Pillsbury, Ruby, Lippens and Irwin. There is marked parallelism between these percentage figures and the descending order established by the net indices of column $\mathrm{C}$.

If we interpret the similar trends of the various columns in terms of probable cause and effect we can conclude that the net variation index of a mango variety depends in part on its total variation index, in part on the tendency for most trees of that variety to respond in concert during any given year. This can be stated inversely by saying that consistency in the bearing habit of a variety apparently depends not only on the relative consistency of the individual trees but also on the fact that on any given year some trees of the variety will "zig" while others "zag" thereby cancelling out much of the possible yearly fluctuation.

We doubtlessly could use any of these indices to rate varieties with respect to consistency of bearing. The net index derived from the varietal mean, however, undoubtedly reflects most precisely that attribute most directly related to economic returns. These yearly indices were subjected to analysis of variance to determine the significance of differences between the mean indices for each variety. These comparisons are shown in table 3. As may be appreciated in this table, the varieties can be classified into three groups. Kent, Eldon, Palmer, Haden, and Keitt constitute the highly inconsistent group 1. Sensation, Santaella, Parvin, Earlygold, and Jacquelin constitute the intermediately inconsistent group 2. Edward, Zill, Pillsbury, Ruby, Lippens, and Irwin constitute group 3, which is consistent in bearing. There are no significant differences within these groups, and yet, all of the highly inconsistent varieties of group 1 have significantly higher indices than those of group 3.

For comparing the varieties with regard to productivity, the totals for all six crops were subjected to analysis of variance wherein the means for each variety were determined using each tree as a separate observation. However, the analysis also segregated the effect of blocks, which proved to be considerable, giving an $F$ value of 20.5 . This was highly significant and much greater than the $F$ value for varieties, which amounted to 8.74 and also highly significant. The varietal means were therefore adjusted to remove the effect of blocks.

In table 4 are shown the original varietal means in terms of a single tree and also their equivalents after adjustment for the effect of blocks. The number of trees which were observed separately for each variety is also shown. The varieties have been placed in descending order in accordance 
TABLE 3.-Comparisons between bearing indices based on differences between varielal means1

\begin{tabular}{|c|c|c|c|c|c|c|c|c|c|c|c|c|c|c|c|c|}
\hline \multirow{2}{*}{\multicolumn{2}{|c|}{$\begin{array}{l}\text { Variety and } \\
\text { mean index }\end{array}$}} & \multicolumn{15}{|c|}{ Variety and mean index } \\
\hline & & $\underset{154}{\text { Kent }}$ & $\begin{array}{c}\text { Eldon } \\
138\end{array}$ & $\underset{131}{\text { Palmer }}$ & $\begin{array}{c}\text { Haden } \\
131\end{array}$ & $\begin{array}{c}\text { Keitt } \\
118\end{array}$ & $\begin{array}{l}\text { Sensa- } \\
\text { tion } 89\end{array}$ & $\underset{80}{\text { Santaella }}$ & $\underset{75}{\text { Parvin }}$ & $\begin{array}{l}\text { Early- } \\
\text { gold } 65\end{array}$ & $\underset{65}{\text { Jacquelin }}$ & $\underset{59}{\text { Edward }}$ & $\underset{57}{\text { Zill }}$ & $\begin{array}{c}\text { Pills- } \\
\text { bury } 51\end{array}$ & $\underset{45}{\text { Ruby }}$ & Lippens $_{40}$ \\
\hline & & \multicolumn{15}{|c|}{ Varielal differences } \\
\hline Kent & 154 & & & & & & & & & & & & & & & \\
\hline Eldon & 138 & 16 & & & & & & & & & & & & & & \\
\hline Palmer & 131 & 23 & 07 & & & & & & & & & & & & & \\
\hline Faden & 131 & 23 & 07 & 00 & & & & & & & & & & & & \\
\hline Keitt & 118 & 36 & 20 & 13 & 13 & & & & & & & & & & & . \\
\hline Sensation & 89 & 65 & 40 & 12 & 42 & 29 & & & & & & & & & & $:$ \\
\hline $\begin{array}{l}\text { Santsella } \\
\text { Parvin }\end{array}$ & $\begin{array}{l}80 \\
75\end{array}$ & $\begin{array}{l}74 \\
79\end{array}$ & $\begin{array}{l}58 \\
63\end{array}$ & $\begin{array}{l}51 \\
66\end{array}$ & $\begin{array}{l}51 \\
56\end{array}$ & $\begin{array}{l}38 \\
43\end{array}$ & $\begin{array}{l}09 \\
14\end{array}$ & 05 & & & & & & & & \\
\hline Earlygold & 65 & 89 & 73 & 66 & 66 & 53 & 24 & 15 & 10 & & & & & & & $\therefore$ \\
\hline Jacquelin & 65 & 89 & 73 & 66 & 66 & 53 & 24 & 15 & 10 & $\infty$ & & & & & & $\because$ \\
\hline Edward & 59 & 95 & 70 & 72 & 72 & 59 & 30 & 21 & 16 & 06 & 08 & & & & & \\
\hline Zill & 57 & 87 & 81 & 74 & 74 & 61 & 32 & 23 & 18 & 08 & 08 & 02 & & & & \\
\hline Pillsbury & 51 & 103 & 87 & 80 & 80 & 67 & 38 & 29 & 24 & 14 & 14 & 08 & 06 & & & \\
\hline Ruby & 45 & 109 & 93 & 86 & 86 & 73 & 44 & 35 & 30 & 20 & 20 & 14 & 12 & 06 & & \\
\hline Lippens & 40 & 114 & 98 & 91 & 91 & 78 & 49 & 40 & 35 & 25 & 25 & 19 & 17 & 11 & 05 & \\
\hline Irwin & 39 & 115 & 99 & 92 & 82 & 78 & 50 & 41 & 36 & 26 & 26 & 20 & 18 & 12 & 06 & 01 \\
\hline
\end{tabular}

1 Differences below the solid line are significant at the 1-percent level and those between the broken and the solid lines at the 5-percent level. 
with the adjusted yields. As may be observed, the adjustments for the effect of blocks were fairly substantial. The largest adjustment was made on variety Kent, in which the mean production per tree was reduced by 146.16 pounds. This variety had only four of its 29 trees located in poor soil blocks of the field and all the other trees were in good soil. Fairly sizable adjustments also were made for four other varieties as follows: For Sensation, the mean production per tree was reduced by 84.32 pounds; Earlygold increased by 99.88 pounds; Santaella, decreased by 83.36 pounds and Edward, increased by 67.09 pounds. Only two other adjustments, those for

TABLE 4.-Mean tolal production per tree in the first six crops of each mango variety before and after adjustment to discount the effect of block location on yields

\begin{tabular}{lcccc}
\hline \multicolumn{1}{c}{ Variety } & $\begin{array}{c}\text { Number of } \\
\text { observations }\end{array}$ & $\begin{array}{c}\text { Initial mean } \\
\text { production per tree }\end{array}$ & $\begin{array}{c}\text { Adjustment } \\
\text { for blocks }\end{array}$ & $\begin{array}{c}\text { Adjusted mean } \\
\text { per tree }\end{array}$ \\
\hline Ruby & Trees & Pounds & Pounds & Pounds \\
Sensation & 31 & 600.15 & -24.97 & 575.18 \\
Eldon & 27 & 639.34 & -84.32 & 555.02 \\
Lippens & 29 & 561.24 & -6.34 & 554.90 \\
Irwin & 31 & 539.51 & +9.87 & 549.38 \\
Earlygold & 32 & 546.85 & -10.55 & 536.30 \\
Keitt & 31 & 400.25 & +99.88 & 500.13 \\
Parvin & 25 & 473.34 & +9.80 & 483.14 \\
Zill & 31 & 452.53 & +30.11 & 482.64 \\
Haden & 31 & 404.69 & +65.83 & 470.52 \\
Palmer & 31 & 401.52 & +55.64 & 457.16 \\
Pillsbury & 28 & 414.51 & +18.68 & 433.19 \\
Kent & 27 & 321.87 & +28.87 & 350.74 \\
Edward & 29 & 493.81 & -146.16 & 347.65 \\
Santaella & 31 & 244.89 & +67.09 & 311.98 \\
Jacquelin & 26 & 371.24 & -83.36 & 287.88 \\
& 30 & 283.00 & -30.55 & 252.45 \\
Total & 470 & $7,148.74$ & & \\
\hline
\end{tabular}

Haden and Zill which received increases, exceeded 50 pounds and of the remainder only two others exceeded 25 pounds.

Table 5 shows comparisons between the adjusted varietal means and indicates which differences are significant. The significance of these comparisons can best be summarized by designating the varieties into three groups as follows: a group of five varieties which gave high yields, a second group of six which gave intermediate yields, and a third group of five which gave low yields. There were no significant differences between varieties within these groups but all the high yielding group, which included Ruby, Sensation, Eldon, Lippens, and Irwin in that order, gave yields which exceeded those of the low group by highly significant differences. The low 
TABLE 5.-Comparison belween varielal means for lolal yield in six crops per single tree afler corvection for regression on experimental blockst

\begin{tabular}{|c|c|c|c|c|c|c|c|c|c|c|c|c|c|c|c|c|c|}
\hline \multirow{2}{*}{\multicolumn{2}{|c|}{$\begin{array}{l}\text { Variety and } \\
\text { corrected mean } \\
\text { (pounds) }\end{array}$}} & \multicolumn{16}{|c|}{ Variety and corrected mean (pounds) } \\
\hline & & Ruby & Sensation & Eldon & Lippens & Irwin & Early- & Keitt & Parvin & Zill & Haden & Palmer & Pills- & Kent & Edward & Santaella & Jac- \\
\hline & & \multicolumn{16}{|c|}{ Varielal differences } \\
\hline Ruby & 575.18 & & & & & & & & & & & & & & & & \\
\hline Sensation & 655.02 & 20.16 & & & & & & & & & & & & & & & \\
\hline Eldon & 554.90 & 20.28 & 0.12 & & & & & & & & & & & & & & \\
\hline Lippens & 540.38 & 25.80 & 5.64 & 5.52 & & & & & & & & & & & & & \\
\hline Irwin & 536.30 & 38.88 & 18.72 & 18.60 & 13.08 & & & & & & & & & & & & \\
\hline Earlygold & 500.13 & 75.05 & 54.89 & 54.77 & 49.25 & 36.17 & & & & & & & & & & & \\
\hline Keitt & 483.14 & 92.04 & 71.88 & 71.76 & 66.24 & 53.16 & 16.98 & & & & & & & & & & \\
\hline Parvin & 482.64 & 92.54 & 72.38 & 72.26 & 66.74 & 53.66 & 17.49 & .50 & & & & & & & & & \\
\hline Zill & 470.52 & 104.66 & 84.50 & 84.38 & 78.86 & 65.78 & 29.01 & 12.62 & 12.12 & & & & & & & & \\
\hline Haden & 457.16 & 118.02 & 97.86 & .97 .74 & 92.22 & 79.14 & 42.97 & 25.98 & 25.48 & 13.36 & & & $\therefore$ & & & & · \\
\hline Palmer & 433.10 & 141.89 & 121.83 & 121.71 & 116.19 & 103.11 & 66.94 & 49.95 & 49.45 & 37.33 & 23.97 & & & & & & \\
\hline Pillsbury & 350.74 & 224.44 & 204.28 & 204.16 & 198.64 & 185.56 & 140.39 & 132.40 & 131.00 & 119.78 & 106.42 & 82.45 & & & & & \\
\hline Tíent & 347.65 & 227.53 & 207.37 & 207.25 & 201.73 & 188.65 & 152.48 & 135.49 & 134.00 & 122.87 & 100.51 & 85.54 & 3.09 & & & & \\
\hline Idward & 311.98 & 263.20 & 243.04 & 242.92 & 237.40 & 224.32 & 188.15 & 171.16 & 170.60 & 158.54 & 145.18 & 121.21 & 38.70 & 35.67 & & & \\
\hline Santaella & 287.88 & 287.30 & 267.14 & 267.02 & 261.50 & 248.42 & 212.25 & 195.20 & 194.76 & 182.64 & 160.28 & 145.31 & 62.86 & 59.77 & 24,10 & & \\
\hline Jacquelin & 252.45 & 322.73 & 302.57 & 302.45 & 296.93 & 283.85 & 247.68 & 230.69 & 230.19 & 218.07 & 204.71 & 180.74 & 08.29 & 95.20 & 50.53 & 35.43 & \\
\hline
\end{tabular}

1 Differences below the solid line are significant at the 1-percent level and those between tho broken and the solid lines at the 5-percent level.- 
yielding group included the varieties Pillsbury, Kent, Edward, Santaella and Jacquelin in that order, and the intermediate group included Earlygold, Keitt, Parvin, Zill, Haden, and Palmer in that order. Ruby, with the highest yield, also surpassed the lowest of the intermediate group, Palmer, at the 5-percent level of significance. All of the varieties of the intermediate group surpassed the yield of Jacquelin at the 1-percent level

TABLE 6.-Yearly yields per tree adjusted in accordance with tolals adjusted for effect of blocks 1

\begin{tabular}{|c|c|c|c|c|c|c|c|}
\hline \multirow{2}{*}{ Variety } & \multicolumn{6}{|c|}{ Adjusted yields (pounds)- } & \multirow{2}{*}{$\begin{array}{c}\text { Adjusted } \\
\text { totals }\end{array}$} \\
\hline & 1965 & 1966 & 1967 & 1968 & 1969 & 1970 & \\
\hline Ruby & 13.80 & 15.82 & 86.48 & 85.58 & 188.20 & 185.30 & 575.18 \\
\hline Sensation & 29.33 & 6.68 & 102.20 & 109.92 & 75.22 & 231.67 & 555.02 \\
\hline Eldon & 32.48 & 8.03 & 95.20 & 154.44 & 27.47 & 237.28 & 554.90 \\
\hline Lippens & 28.01 & 28.55 & 60.99 & 119.50 & 124.86 & 187.47 & 549.38 \\
\hline Irwin & 28.25 & 27.93 & 101.94 & 91.30 & 115.60 & 171.28 & 536.30 \\
\hline Earlygold & 16.21 & 24.99 & 93.36 & 53.28 & 130.15 & 182.14 & 500.13 \\
\hline Keitt & 20.62 & 4.09 & 88.53 & 106.73 & 32.76 & 230.41 & 483.14 \\
\hline Parvin & 12.89 & 6.66 & 87.06 & 92.75 & 68.44 & 214.84 & 482.64 \\
\hline Zill & 12.43 & 27.53 & 110.98 & 81.87 & 86.21 & 151.50 & 470.52 \\
\hline Haden & 35.64 & 4.04 & 66.54 & 105.85 & 26.87 & 218.22 & 457.16 \\
\hline Palmer & 16.61 & 0.35 & 53.06 & 105.59 & 47.06 & 210.52 & 433.19 \\
\hline Pillsbury & 23.98 & 17.92 & 70.79 & 91.13 & 87.12 & 59.80 & 350.74 \\
\hline Kent & 33.91 & .77 & 43.47 & 89.85 & 12.79 & 166.86 & 347.65 \\
\hline Edward & 6.13 & 27.14 & 54.80 & 42.53 & 85.19 & 96.19 & 311.98 \\
\hline Santaella & 8.37 & 6.13 & 49.55 & 79.67 & 31.78 & 112.38 & 287.88 \\
\hline Jacquelin & 3.96 & 8.16 & 32.73 & 28.98 & 71.07 & 107.55 & 252.45 \\
\hline Total & 322.62 & 214.79 & $1,197.68$ & $1,438.97$ & $1,210.79$ & $2,763.41$ & $7,148.26$ \\
\hline
\end{tabular}

1 Adjusted yield for each year was obtained by dividing the adjusted totals for the 6 years by the actual totals before adjustment and then multiplying by the yearly crops. When adjusted in this manner the yearly totals necessarily differ slightly from the original yearly totals.

of significance and that of Santaella at the 5-percent level or higher. The first five of the intermediate group (Earlygold, Keitt, Parvin, Zill and Haden) surpassed Edward at the 5-percent level of significance and of these Earlygold also surpassed it at the 1-percent level. In addition, Earlygold surpassed both Pillsbury and Kent at the 5-percent level of significance.

Because most horticulturists think in terms of yearly crops, table 6 is included to show how the adjustment made on the 6-year totals can be apportioned among the six yearly crops which comprise these totals. As may be appreciated, the yearly totals for all varieties necessarily must 
vary somewhat from the original yearly totals but the variety totals remain unchanged.

It should be emphasized that these yield comparisons have thus far been made strictly on a single-tree basis. To convert these to per acre yields we could simply multiply by 70 , which would provide the expected per acre yield at the 25 feet $\times 25$ feet spacing regarded as good commercial spacing for most mangos. However, as mentioned previously, we have annotated different tree-size measurements in this experiment and found that some varieties grow much more rapidly than others. Obviously, tree size and rate of growth will affect per acre yields. Preferably, slow growing varieties which produce smaller trees should be planted at closer spacing than faster growing varieties which produce large trees in a shorter time. Even when planted at equal, commercially desirable distances, such as 25 feet $\times 25$ feet or slightly closer, varieties with rapid tree growth would require earlier and more severe pruning to prevent the interlacing of branches from adjacent trees. Thus tree size in any case would affect per acre yields in favor of varieties having the smallest trees.

Because of the difficulties involved in attempting to calculate the depressing effect of pruning on yields, we propose to calculate the potential per acre productive capacity of a variety by assigning to it a theoretical planting distance equal to $1 \frac{1}{2}$ times its mean crown diameter at 10 years from planting. This is, of course, somewhat arbitrary and may not be the most appropriate method of basing spacing on tree size. It is, however, at least a fairly acceptable method and results in planting distances not too far removed from what we now believe to be commercially desirable for mango orchards located in similar areas in Puerto Rico. We are not recommending these distances; they are simply used as a device for comparing yields on a per acre basis which takes the tree size and growth rate of the different varieties into account.

The tree crown diameters measured in December 1970 when the trees were 10 years old, were first subjected to analysis of variance using individual trees as separate observations but also segregating the effect of blocks. The $F$ value for varieties amounted to 13.90 and for blocks to 8.64. Both were high significant. The varietal means after adjustment for the effect of blocks are included in table 7 which also shows the differences between them for all combinations, and indicates which of these are significant.

As may be observed in table 7, the mean crown diameter of a 10-year old tree of the different varieties varied from 18.73 feet for Palmer to 12.58 feet for Lippens. The varieties can be classified roughly into four groups as follows: Palmer and Ruby constitute group 1, the largest, with crown 
T.BLE: 7.-Comparison of mean diameter of trec crown after adjustment for effect of blocks ${ }^{1}$

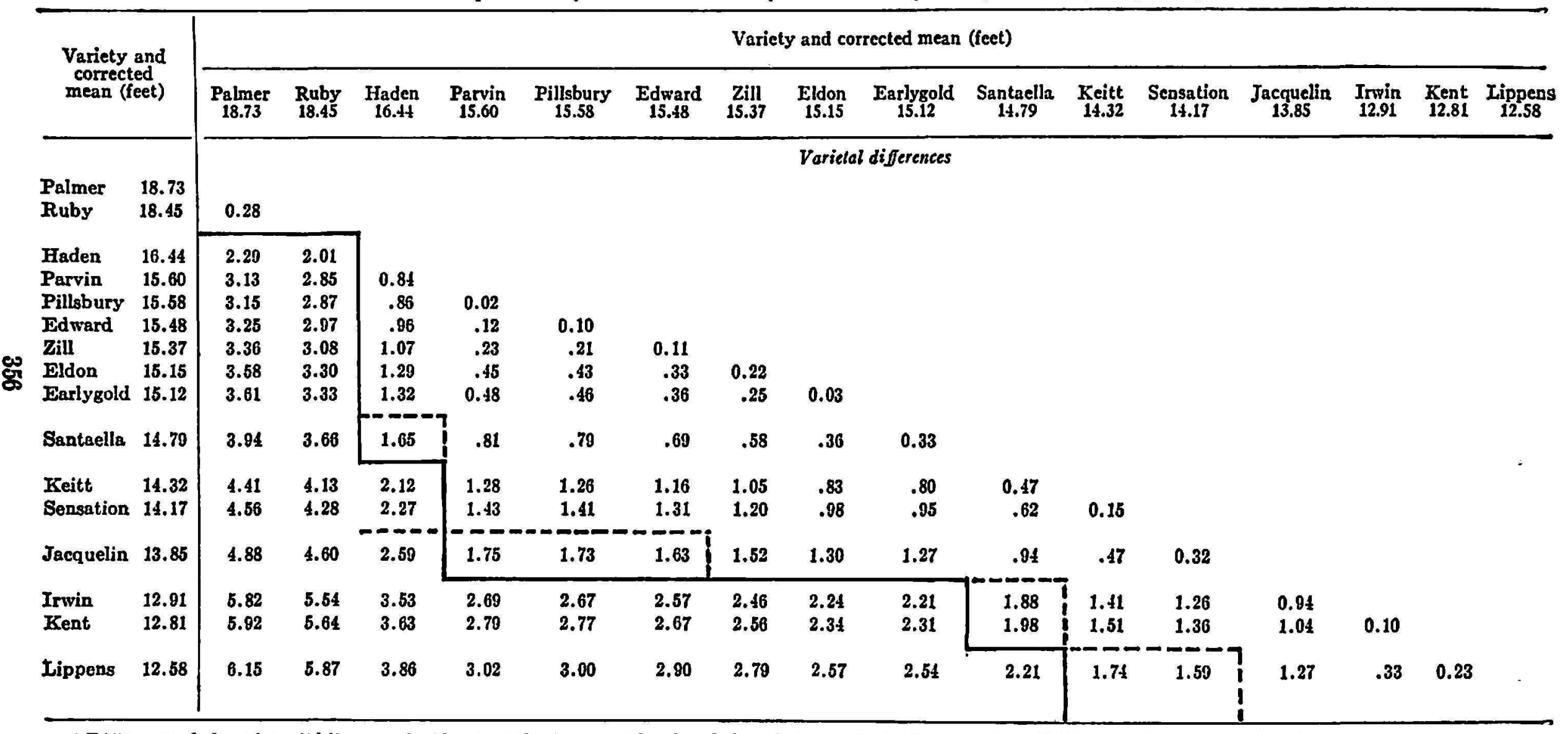

2 Differences below the solid line are significant at the 1-percent level and those between the broken and the solid lines at the 5-percent level. 
diameters greater than 18 feet. Parvin, Pillsbury, Edward, Zill, Eldon, and Earlygold constitute group 2, medium-large in size, with diameters less than 16 feet and over 15 feet. Santaella, Keitt, and Sensation constitute group 3, medium-small in size, with diameters less than 15 feet and over 14 feet. Irwin, Kent and Lippens constitute group 4, the smallest, with diameters less than 13 feet. Haden and Jacquelin are intermediate in size and difficult to place within any group. Haden is the third largest variety with a mean diameter of 16.44 feet, and intermediate between groups 1 and 2. Jacquelin is the fourth smallest tree with a crown diameter of 13.85 feet, which is intermediate between groups 3 and 4. Group 1 exceeds all other varieties by highly significant differences in crown diameters. Group 2 is not significantly different from group 3 but exceeds group 4 by highly significant differences. Haden exceeds group 3 by significant differences in diameter. Jacquelin is not significantly different from group 4 , but not exceeded significantly by group 3 .

Hypothetical distances for planting in square pattern were established for each variety by multiplying its mean crown diameter at 10 years of age by $1 \frac{1}{2}$. The number of trees per acre was then determined to the nearest tenth by dividing 43,560 by the square of the planting distances. The mean yields per tree for each variety were then multiplied by the number of trees per acre thus determined. Table 8 shows the yields per acre for each variety thus obtained and includes the separate annual yields as well as the totals for all six crops. The number of trees per acre used in making the calculations are also shown. The varieties are listed in descending order in accordance with total yields.

The varietal sequence in order of productivity per acre in table 8 is quite different from that of productivity per tree shown in table 6 . Lippens and Irwin which were fourth and fifth on a per-tree basis are now the first and second most productive varieties. Ruby, which was the most productive on a single-tree basis, was lowered to 11 th place on a per-acre basis. It may also be observed that the five most productive varieties Lippens, Irwin, Sensation, Eldon and Keitt, would produce 10 to 11 tons of fruit on the 10th year from planting. The least productive varieties Pillsbury, Santaella, Jacquelin, Edward and Palmer would produce from 21/2 to 6 tons per acre on the 10th year from planting.

The data in table 8 was subjected to analysis of variance to determine the significance of differences between varietal totals. These differences and their significance are shown in table 9. As may be seen in table 9, the varieties can be classified into three groups. The highest-yielding group, which had a total crop below 68,000 pounds and above 45,000 , included varieties Lippens, Irwin, Sensation, Eldon and Keitt, in descending order. The group having medium yields, below 44,000 pounds and above 38,000 


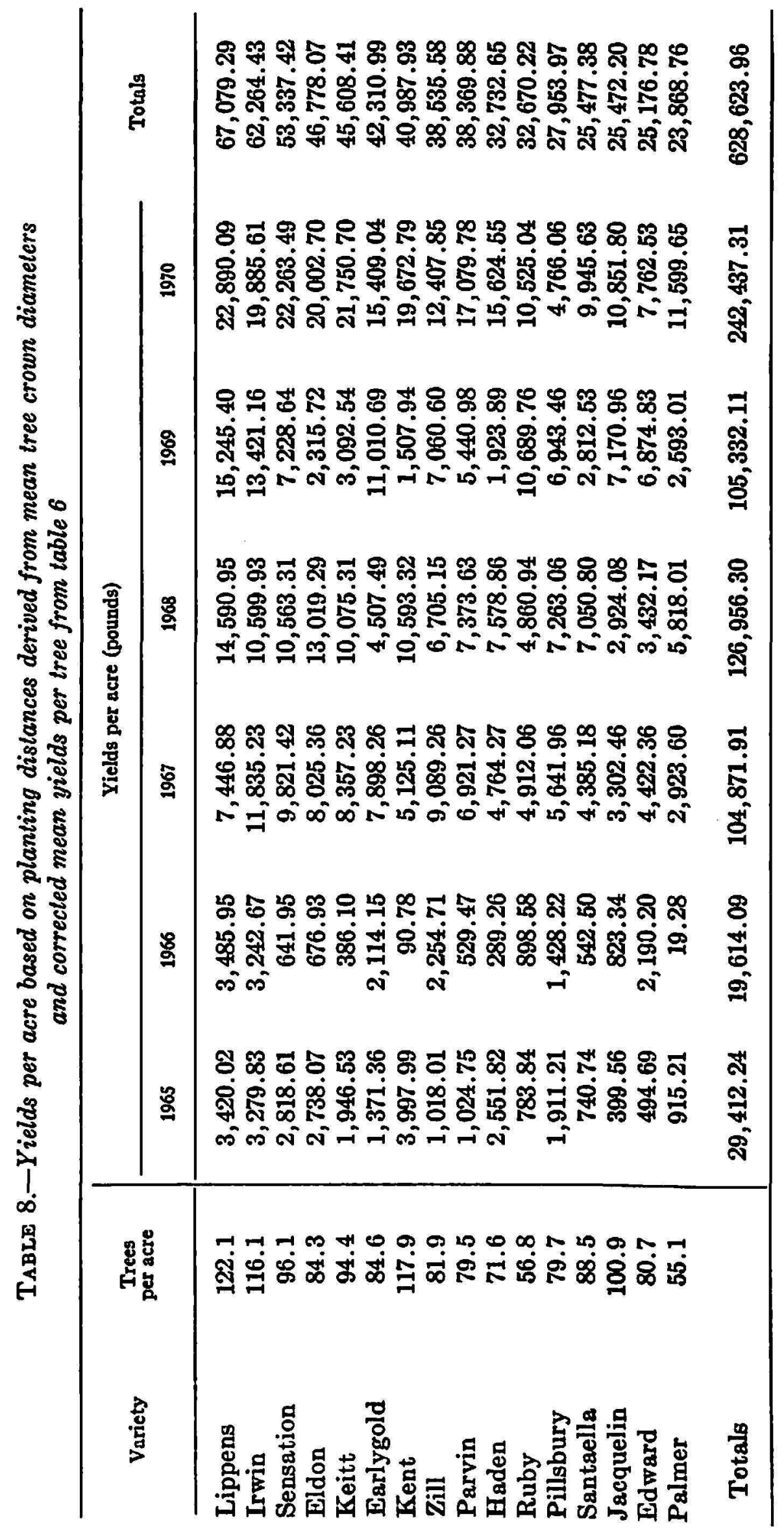


TABLE 9.-Comparisons between per acre tolal yields of varieties from table $8^{\mathbf{1}}$

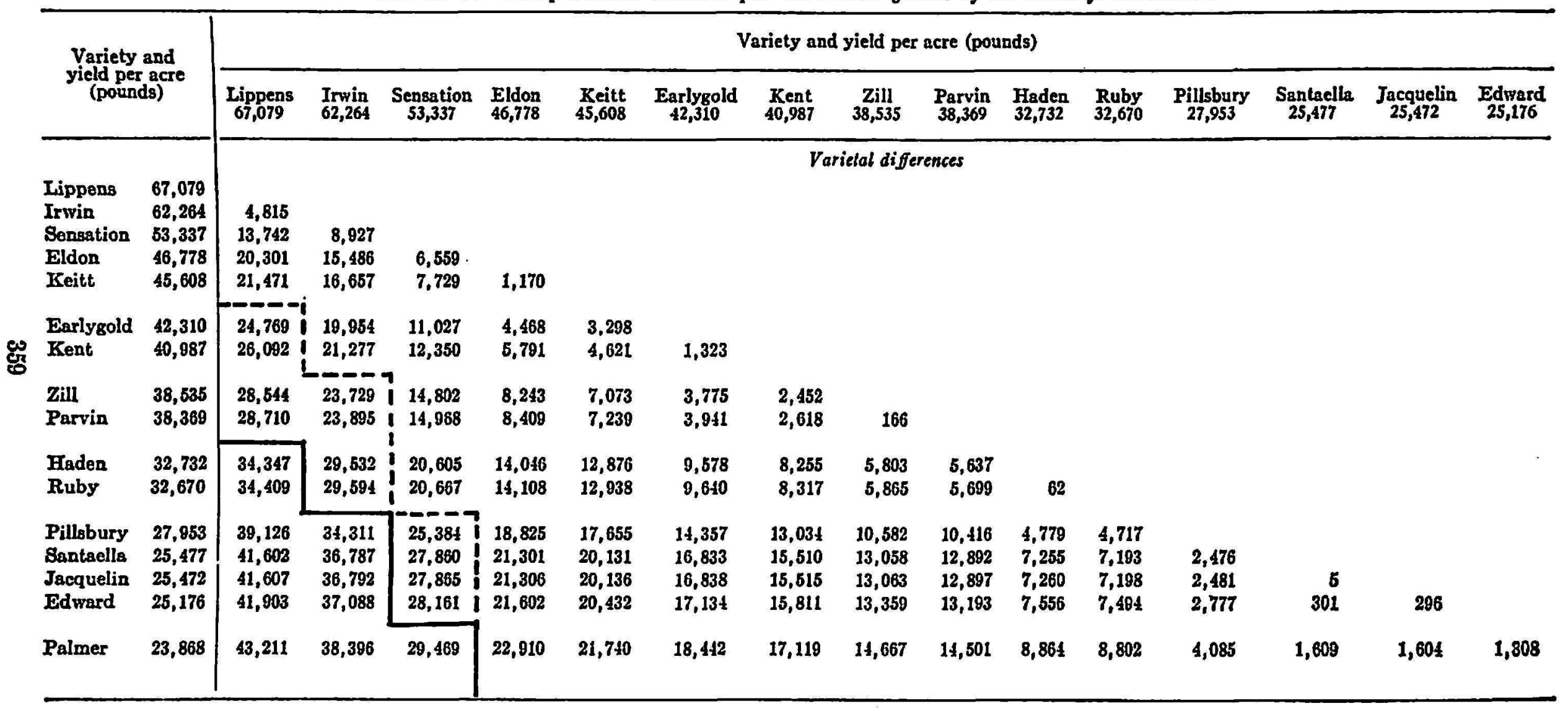

1 Differences below the solid line are significant at the 1-percent level and those between the broken and the solid lines at the 5-percent level. 
included varieties Earlygold, Kent, Zill and Parvin, in descending order. The low yielding group with total yields below 28,000 pounds included varieties Pillsbury, Santaella, Jacquelin, Edward and Palmer, in descending order. There were no significant differences within these groups. The first three varieties in the high-yielding group, Lippens, Irwin, and Sensation, gave significantly higher yields than all of the varieties in the low yielding group.

Fruit size, indicated in table 10 by mean weight in pounds, lists the varieties in descending order for all fruits produced in the first six crops. The mean fruit size for each variety in each crop is also shown as well as their totals and the varietal means derived from these totals. The yearly totals of the mean fruit size for all varieties is also shown as well as the yearly means derived from these totals. The actual yearly means obtained from the primary data are also shown. As may be observed in the table, fruit

TABLE 10.-Mango fruit size indicaled as weight in pounds per fruit

\begin{tabular}{|c|c|c|c|c|c|c|c|c|c|}
\hline Variety & 1965 & 1966 & 1967 & 1968 & 1969 & 1970 & Total & $\begin{array}{c}\text { Derived } \\
\text { means }\end{array}$ & $\begin{array}{l}\text { Actual } \\
\text { means }\end{array}$ \\
\hline Jacquelin & 0.71 & 1.36 & 1.08 & 1.38 & 1.39 & 1.40 & 7.32 & 1.220 & 1.33 \\
\hline Kent & 1.04 & 1.10 & 1.15 & 1.08 & 1.14 & 1.24 & 6.75 & 1.125 & 1.16 \\
\hline Keitt & 1.01 & 1.11 & 1.00 & .97 & 1.14 & 1.15 & 6.38 & 1.063 & 1.07 \\
\hline Palmer & .97 & .92 & .90 & 1.00 & 1.16 & 1.04 & 5.99 & .998 & 1.02 \\
\hline Edward & .85 & .99 & .76 & 1.01 & 1.06 & 1.00 & 5.67 & .945 & .96 \\
\hline Eldon & .74 & 1.01 & .77 & .83 & .91 & .79 & 5.05 & .842 & .80 \\
\hline Parvin & .72 & .59 & .78 & .78 & .91 & .84 & 4.62 & .770 & .82 \\
\hline Haden & .69 & .72 & .53 & .77 & .76 & .75 & 4.22 & .703 & .71 \\
\hline Earlygold & .52 & .65 & .66 & .74 & .75 & .72 & 4.04 & .673 & .70 \\
\hline Irwin & .59 & .71 & .64 & .69 & .65 & .66 & 3.94 & .657 & .66 \\
\hline Zill & .61 & .61 & .59 & .64 & .65 & .62 & 3.72 & .620 & .62 \\
\hline Lippens & .57 & .66 & .57 & .62 & .66 & .61 & 3.69 & .615 & .62 \\
\hline Sensation & .55 & .69 & .58 & .59 & .65 & .60 & 3.66 & .610 & .60 \\
\hline Pillsbury & .56 & .58 & .56 & .57 & .59 & .63 & 3.49 & .582 & .58 \\
\hline Santaella & .46 & .48 & .59 & .52 & .57 & .53 & 3.15 & .525 & .54 \\
\hline Ruby & .47 & .44 & .48 & .47 & .40 & .45 & 2.71 & .452 & .44 \\
\hline Totals & 11.06 & 12.62 & 11.64 & 12.66 & 13.39 & 13.03 & 74.40 & & \\
\hline
\end{tabular}

Size index consisting of means derived from tolals

\begin{tabular}{lllllll}
\hline .691 & .789 & .728 & .791 & .837 & .814 & .775 \\
\hline \multicolumn{6}{c}{ Actual means } \\
\hline .67 & .67 & .66 & .71 & .66 & .74 \\
\hline
\end{tabular}


size varied in different years. For comparing fruit size in different years we prefer to use the mean fruit size indices derived from the totals of the varietal mean sizes. It will be observed that the actual yearly means derived from the primary data are invariably smaller. This undoubtedly is attributable to the larger number of small fruit produced by small-fruited varieties bearing comparable yields on a per-pound basis with larger-fruited varieties. The actual mean fruit weight in any given year is therefore weighted to favor smallness when based on the initial fruit counts. With the yearly means derived from the varietal means, however, each variety is represented equally. This provides a better set of comparable yearly indices of fruit size which are unaffected by the relative abundance of cither small or large-fruited varieties. As may be seen, the yearly size index was quite low in 1965 and 1967 when the mean was just below and just above $7 / 10$ of a pound, whereas in the others it approached $8 / 10$ of a pound. This variation in fruit size can be caused by several factors, including tree size and the amount of its crop, as well as by the abundance of rainfall during the month or two preceding fruit maturity.

For similar reasons we prefer the varietal fruit size indices derived from the totals for comparing the fruit size of the different varieties. Table 11 shows a comparison of these means of the different varieties and indicates whether the differences are significant. The $F$ value for the analysis of variance was 43.47 which was very highly significant. All significant differences are shown in the table. The following discussion is thus limited to the grouping of varieties into different size categories:

Group 1. Large sized fruit with an index that ranges from 1.220 to 0.945 pounds per fruit includes varieties Jacquelin, Kent, Keitt, Palmer and Edward, which diminish in size in that order.

Group 2. Varieties Eldon and Parvin both of which vary considerably in size, are medium large sized fruit with a size index that ranges from 0.842 to 0.770 pounds per fruit.

Group 3. Medium sized fruit with a size index from 0.703 to $\mathbf{0 . 6 5 7}$ includes varieties Haden, Earlygold, and Irwin, which diminish in size in that order.

Group 4. Medium small fruit with a size index from 0.620 to 0.582 includes varieties Zill, Lippens, Sensation and Pillsbury which diminish in size in that order.

Group 5. Small fruit with a size index from 0.525 to 0.425 includes varieties Santaella and Ruby, which diminish in size in that order.

In the large-fruit group, Jacquelin exceeds significantly the size of Keitt, Palmer and Edward, Kent exceeds Palmer and Edward, and Keitt exceeds Edward. Nevertheless, all varieties in the group significantly exceed Eldon 
TaBle 11.-Comparison of varietal mean weights per fruill

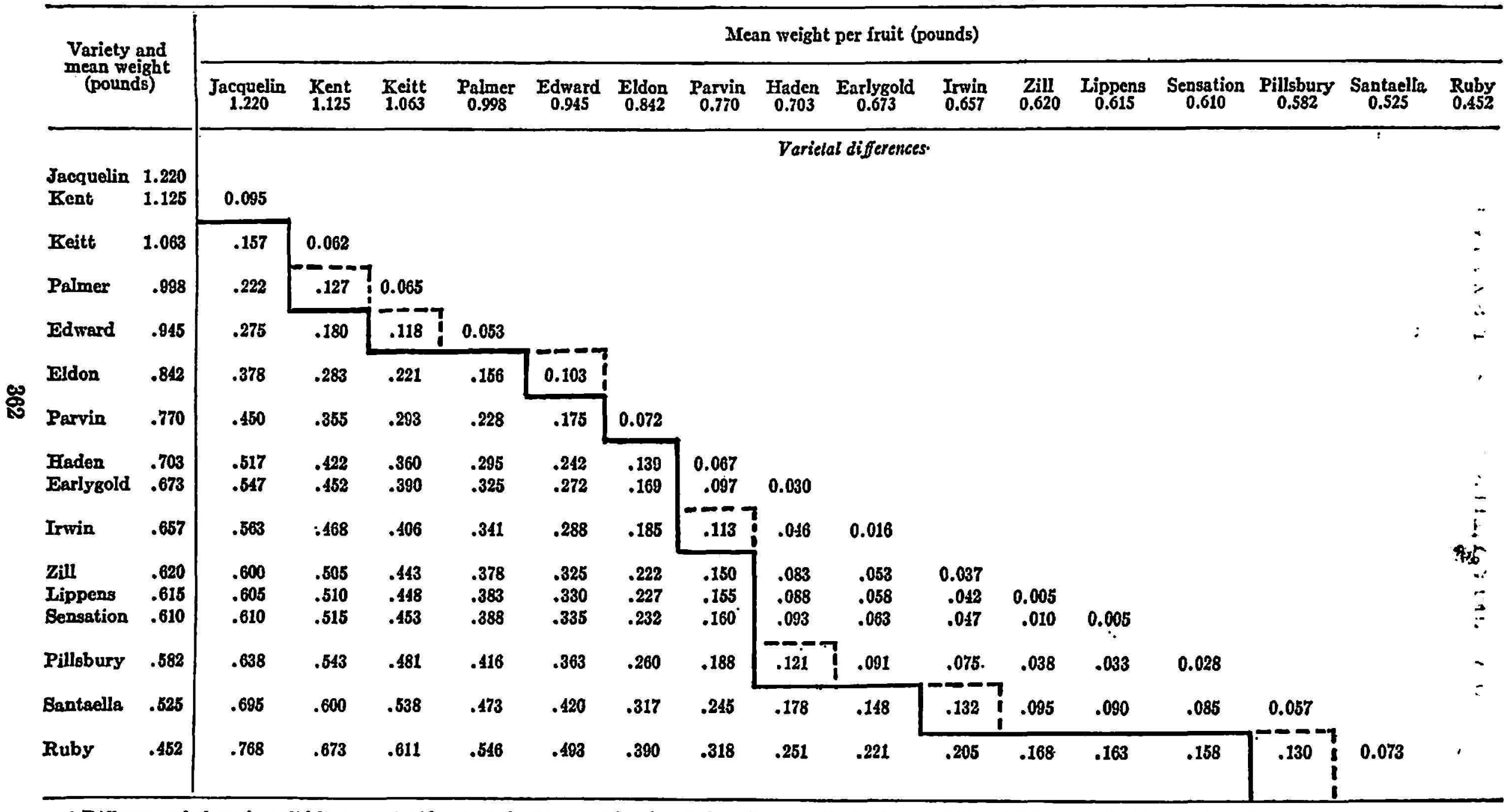

1 Differences below the solid line are significant at the 1-percent level and those between the broken and the solid lines at the 5-percent level. 
and Parvin. There are no significant differences in size within any of the other groups and each group exceeds the following one by a significant difference.

\section{SUMMARY}

Sixteen mango varieties planted at 30 feet by 30 feet spacing in a partially balanced incomplete block design, which included 32 trees of each variety, were compared with respect to production, and fruit and tree size. Production for all varieties in general started on the fifth year after planting when in accordance with linear regression it amounted to 5 pounds of fruit per tree, and increased at the rate of about 28 pounds per year per tree during the following five crops.

The varieties were classified with regard to consistency in bearing, according to a mean index derived from the difference in yield per tree from one year to the next divided by its mean yield for the 2 years being compared. The varieties Kent, Eldon, Palmer, Haden, and Keitt were highly inconsistent. Varieties Sensation, Santaella, Parvin, Earlygold and Jacquelin were intermediately consistent. The varieties Edward, Zill, Pillsbury, Ruby, and Irwin were regular bearers.

The potential productivity per acre for each variety was calculated hypothetically for a square-lattice pattern of planting at a distance of $11 / 2$ times the mean tree-crown diameter at 10 years of age. These distances varied from 28.1 feet for Palmer to $\mathbf{1 8 . 9}$ feet for Lippens. The varieties Lippens, Irwin, Sensation, Eldon and Keitt, in descending order, gave the highest yields ranging in total production for the six crops from 67,079 pounds per acre for Lippens to 45,608 pounds per acre for Keitt. The last crop of these same varieties at 10 years of age ranged from 10 to 11 tons per acre. The varieties Earlygold, Kent, Zill, and Parvin in descending order gave intermediate yields ranging in total production for the six crops from 42,310 pounds per acre for Earlygold to 38,369 pounds per acre for Parvin. The last crop of these same varieties at 10 years of age ranged from 6 to 10 tons per acre. The varieties Haden, Ruby, Pillsbury, Santaella, Jacquelin, Edward and Palmer, in descending order, gave yields at 10 years of age, which ranged from 6 to 10 tons per acre. The varieties Haden, Ruby, Pillsbury, Santaella, Jacquelin, Edward and Palmer in descending order, gave the lowest yields ranging in total production for the six crops from 32,732 pounds per acre for Haden to 23,868 pounds per acre for Palmer. The last crop of these same varieties, at 10 years of age, ranged from $2 \frac{1}{2}$ to 6 tons per acre.

The mean fruit size for each variety was determined in terms of weight in pounds per fruit utilizing all of the available data from the six crops. The varieties Jacquelin, Kent, Keitt, Palmer and Edward, in descending 
order, gave the largest fruit. The size ranged from a mean weight of 1.220 pounds for Jacquelin to 0.945 pounds for Edward. The varieties Eldon, Parvin, Haden, Earlygold, and Irwin, in descending order, gave intermediate sized fruit ranging from 0.842 pounds for Eldon to 0.657 pounds for Irwin. The varieties Zill, Lippens, Sensation, Pillsbury, Santaella, and Ruby, in descending order, gave small fruit ranging from 0.620 pounds for Zill to 0.452 pounds for Ruby.

\section{RESUMEN}

En un experimento en que se utilizó un diseño parcialmente compensado de bloques incompletos, se sembraron 32 árboles de cada una de 16 variedades de mango a una distancia de 30 pies $\times 30$ pies, para comparar su rendimiento y el tamaño del árbol y de la fruta. Todas las variedades comenzaron a producir al quinto año después de sembradas. De acuerdo con una regresión lineal el rendimiento medio por árbol en la primera cosecha fue de 5 libras, aumentando a razón de 28 libras por año durante los 5 años siguientes.

Las variedades se clasificaron según la consistencia de su producción, la cual se estimó mediante un índice basado en la diferencia entre los rendimientos por árbol en dos años consecutivos, dividida por la producción media de los 2 años que se comparaban. Las variedades Kent, Eldon, Palmer, Haden y Keitt fueron muy inconsistentes en su producción; las variedades Sensation, Santaella, Parvin, Earlygold y Jacquelin, de consistencia intermedia; y las variedades Edward, Zill, Pillsbury, Ruby y Irwin a su vez, las más consistentes.

La potencialidad productiva por acre de cada variedad se estimó hipotéticamente para una siembra en cuadros a una distancia de vez y media el diámetro de la copa del árbol a los 10 años de edad. Estas distancias variaron de 28.1 pies para la variedad Palmer a 18.9 pies para la Lippens. Las variedades Lippens, Irwin, Sensation, Eldon y Keitt fueron, en orden descendẹte, las que más produjeron. La producción total estimada de cada una para las seis cosechas varió de 67,079 libras por acre para la Lippens a 45,608 para la Keitt. La última cosecha de estas variedades a los 10 años de edad varió de 10 a 11 toneladas por acre. Las variedades Earlygold, Kent, Zill y Parvin, también en orden descendente, tuvieron producciones intermedias, con un total para las seis cosechas, que varió de 42,310 libras por acre para la Earlygold a 38,369 para la Parvin. La última cosecha de estas variedades a los 10 años de edad varió de 6 a 10 toneladas por acre. En orden descendente, las variedades Haden, Ruby, Pillsbury, Santaella, Jacquelin, Edward y Palmer produjeron los rendimientos más bajos, con una producción total para las seis cosechas que varió de 32,732 libras por acre para la Haden a 23,868 para la Palmer. En éstas, la última cosecha a los 10 años de edad varió de $2 \frac{1}{2}$ a 6 toneladas por acre.

El tamaño medio de la fruta de cada variedad se expresó en libras por unidad, basándose en todos los datos obtenidos durante las seis cosechas. Las variedades Jacquelin, Kent, Keitt, Palmer y Edward, en orden descendente, produjeron las frutas más grandes, que variaron en peso medio de 1.220 libras para la. Jacquelin a 0.945 libra para la Edward; por fruta. Las variedades Eldon, Parvin, Haden, Earlygold y Irwin, en orden descendente, produjeron frutas de tamaño intermedio, con un peso que varió de 0.842 libra para la Eldon a 0.657 libra para la Irwin, por fruta. Las frutas más pequeñas se obtuvieron de las variedades Zill, Lippens, Sensation, Pillsbury, Santaella y Ruby, cuyos pesos, en orden descendente, variaron de 0.620 libra para la Zill a 0.450 para la Ruby, por fruta. 